\title{
Influência da declividade do solo e da energia cinética de chuvas simuladas no processo de erosão entre sulcos ${ }^{1}$
}

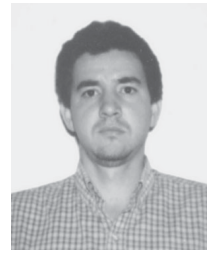

Ricardo S.S. Amorim² ${ }^{2}$, Demetrius D. da Silva ${ }^{3}$, Fernando F. Pruski ${ }^{4}$ \& Antonio T. de Matos ${ }^{5}$

1 Parte da Dissertação de Mestrado do primeiro autor

2 DEA/UFV. Fone: (31) 3899-2715. E-mail: rsamorim@alunos.ufv.br (Foto)

${ }^{3}$ DEA/UFV. Fone: (31) 3899-1904. E-mail: david@mail.ufv.br

4 DEA/UFV. Fone: (31) 3899-1912. E-mail: ffpruski@mail.ufv.br

5 DEA/UFV. Fone: (31) 3899-1886. E-mail: atmatos@mail.ufv.br

Protocolo $045-24 / 04 / 2000$

\begin{abstract}
Resumo: Utilizou-se um simulador de chuvas e um canal de solo para se avaliar o efeito da declividade da superfície do solo e da energia cinética decorrente das chuvas simuladas nas perdas de solo em áreas entre sulcos. O experimento consistiu de um esquema fatorial, com cinco valores de energia cinética $\left(495,832,1.151,1.541 \mathrm{e} 1.959 \mathrm{~J} \mathrm{~m}^{-2}\right.$ ) correspondentes às intensidades de precipitação de $30,46,69,88$ e $107 \mathrm{~mm} \mathrm{~h}^{-1}$, respectivamente, e cinco declividades da superfície do solo (2, 6, 10, 14 e 18\%). Nos testes foi utilizado o horizonte $A$ de um Latossolo Vermelho-Amarelo. A perda de solo foi determinada pelo método direto e uma equação de regressão foi obtida, tendo-se como variável dependente a perda de solo e, como variáveis independentes, a declividade da superfície do solo e a energia cinética da precipitação. Os resultados mostraram que a perda acumulada de solo ao longo do tempo apresentou comportamento com tendência linear proporcionando, desta forma, taxas de perda de solo constantes ao longo dos testes e que a perda total de solo aumentou à medida que os valores de declividade da superfície do solo e energia cinética foram aumentados, sendo que o efeito da declividade na perda de solo foi menos expressivo que o da energia cinética.
\end{abstract}

Palavras-chave: energia cinética, declividade, chuva simulada, erosão entre sulcos

\section{Influence of the soil slope and kinetic energy of simulated precipitation in the channel interrill erosion process}

\begin{abstract}
A rainfall simulator and a soil channel were used to evaluate the effect of the soil slope and kinetic energy of simulated rainfall on the soil loss for interrill areas. The experiment consisted of a factorial arrangement, with five values of kinetic energy $\left(495,832,1,151,1,541\right.$ e 1,959 $\mathrm{J} \mathrm{m}^{-2}$ ) corresponding to precipitation intensities of $30,46,69,88$ and $107 \mathrm{~mm} \mathrm{~h}^{-1}$, respectively, and five soil slopes $(2,6,10,14$ and $18 \%)$. In the test, a horizon of a Red Yellow Latosol soil was used. The soil loss was determined by direct method and a regression equation was obtained relating the soil loss with the soil slope and kinetic energy. The results showed that the accumulated soil loss with time presented a tendency towards linearity providing, this way, soil loss rates constant through out the tests; and the total soil loss increased with the increase of the soil slope and of the kinetic energy, but the slope had a less expressive effect on soil loss than the precipitation kinetic energy.
\end{abstract}

Key words: kinetic energy, slope, rain simulation, erosion interrill

\section{INTRODUÇ̃̃̃O}

A erosão consiste no processo de desprendimento e transporte das partículas do solo, constituindo-se na principal causa da degradação dos solos trazendo, como conseqüência, prejuízos ao setor agrícola e ao meio ambiente, com reflexos tanto econômicos quanto sociais.

Além das partículas de solo em suspensão, o escoamento superficial transporta nutrientes, matéria orgânica, sementes e defensivos agrícolas que, além de acarretar o empobrecimento gradativo dos solos agrícolas, gera a elevação do custo de produção podendo, inclusive, resultar no abandono de áreas anteriormente produtivas (Bertoni \& Lombardi Neto, 1990; Parker et al., 1995).

$\mathrm{Na}$ erosão hídrica, a desagregação das partículas de solo na superfície é uma ação provocada pela energia de impacto das gotas da chuva e pela força cisalhante do escoamento superficial. O domínio da energia de impacto das gotas da chuva ou do escoamento superficial no desprendimento e transporte de sedimentos, depende se a erosão ocorre em sulcos ou em áreas entre sulcos.

A erosão em sulcos resulta da concentração do escoamento superficial produzido por uma chuva, ocasionando a formação 
de pequenos canais que podem ser facilmente desfeitos pelas práticas de cultivo. Foster (1982) caracteriza a erosão em sulcos quando se tem a formação de sulco com uma profundidade máxima de $300 \mathrm{~mm}$. Nas áreas de ocorrência da erosão em sulcos, há domínio da ação erosiva decorrente da energia associada ao escoamento, sendo a energia de impacto das gotas da chuva no desprendimento usualmente considerada desprezível.

A erosão entre sulcos é, às vezes, referida como erosão laminar; este processo promove a remoção de finas camadas de solo, da superfície do solo, uma após a outra, e a erosão não é claramente evidenciada por simples inspeção visual. $\mathrm{Na}$ erosão entre sulcos, os mecanismos de impacto das gotas da chuva na superfície do solo e o escoamento superficial são, conjuntamente, os responsáveis pelo desprendimento e transporte de sedimentos.

A erosão entre sulcos é um processo complexo e a intensidade com que ela ocorre depende, basicamente, de três fatores: das características da chuva, das características do solo e das características da superfície do solo (Watson \& Laflen, 1986).

A erosividade da chuva, a qual representa a capacidade potencial da chuva em provocar o processo de erosão do solo, tem sido usualmente expressa como uma função potencial da intensidade de precipitação (Meyer \& Wischmeier, 1969). Diversos pesquisadores conduziram trabalhos em laboratório para avaliar o efeito da energia de impacto das gotas e da intensidade da precipitação na erosão entre sulcos, verificando que ambas têm alta correlação com este tipo de erosão; no entanto, Meyer \& Harmon (1992) estudando o efeito da intensidade e energia de impacto das gotas da precipitação, evidenciaram que precipitações artificiais de mesma intensidade e duração de 30 min produziram perdas de solo cerca de três vezes menores quando a energia cinética da precipitação foi reduzida em torno de 57\%. Esses autores evidenciaram, ainda, a importância do conhecimento da energia cinética da precipitação aplicada por simuladores de chuvas, utilizada nos estudos do processo de erosão entre sulcos, visto que a taxa de erosão pode ser várias vezes maior para condições de chuva natural, quando comparadas com as chuvas artificiais, caso a precipitação simulada possua características de tamanho de gotas, velocidade terminal de gotas e energia cinética inferiores às das chuvas naturais.

O processo de erosão entre sulcos é bastante afetado pelas condições da superfície do solo, como existência de vegetação ou cobertura morta, microtopografia e/ou rugosidade da superfície do solo e declividade da superfície do solo.

Pouca importância tem sido dada ao efeito da declividade da superfície do solo na erosão em áreas entre sulcos, sendo prática comum relacionar-se a taxa de erosão para estas áreas, como função do quadrado da intensidade de precipitação (Kinnell \& Cummings, 1993); no entanto, Watson \& Laflen (1986) constataram que o aumento da declividade da superfície do solo aumenta a erosão nas áreas entre sulcos, embora não seja com o mesmo grau em que ocorre na erosão em sulcos.
Lattanzi et al. (1974) verificaram que, quando a declividade da superfície do solo foi aumentada de 2 para $20 \%$, a erosão entre sulcos de um solo siltoso aumentou mais que o dobro. Bryan (1979) avaliando 10 tipos de solo em uma faixa de 5 a $58 \%$ de declividade, observou que, para a maioria dos casos, uma função polinomial de segundo grau representou bem a relação entre erosão entre sulcos e a declividade da superfície do solo. Lang et al. (1984) encontraram que a erosão entre sulcos de um "topossolo" foi maior para 9\% de declividade que em 3\%.

Com base no enfoque exposto anteriormente, os objetivos deste estudo foram: avaliar o comportamento da perda acumulada de solo ao longo do tempo de precipitação para diferentes valores de energia cinética decorrentes de chuvas simuladas e de declividade da superfície do solo; verificar o efeito da declividade e da energia cinética na perda total de solo e ajustar equações para a estimativa das perdas de solo, entre sulcos, em função desses dois fatores.

\section{MATERIAL E MÉTODOS}

O experimento foi conduzido na área do Laboratório de Hidráulica do Departamento de Engenharia Agrícola da Universidade Federal de Viçosa, em Viçosa, MG.

Os ensaios foram realizados utilizando-se um canal de solo, no qual foi colocada uma camada de solo de aproximadamente $150 \mathrm{~mm}$ de altura. Entre o fundo do canal e a camada de solo colocou-se uma camada de areia de $50 \mathrm{~mm}$, para facilitar a drenagem da água aplicada durante o preparo do solo no canal e no momento da realização da saturação prévia do solo, antes de cada ensaio. O solo foi passado em peneira de $4,5 \mathrm{~mm}$, após ser secado ao ar por um período de 2 dias e, posteriormente, acomodado sobre o canal, em três camadas de $5 \mathrm{~cm}$ cada uma. As camadas foram compactadas individualmente, a partir da carga exercida com a queda de um peso de $10 \mathrm{~kg}$ de uma altura de $600 \mathrm{~mm}$, em uma chapa de aço (nas mesmas dimensões do canal de solo) colocada sobre o solo.

A compactação foi feita de forma que a massa específica do solo no canal se aproximasse da massa específica existente em condições de campo. Foram feitas ranhuras entre as camadas de solo após a compactação de cada camada, para evitar a formação, entre as mesmas, de caminhos preferenciais de escoamento. A massa de solo colocada em cada camada foi calculada em função do volume de cada camada e da massa específica obtida nos testes preliminares de compactação. Primeiramente, colocaram-se $80 \%$ da massa de solo calculada e se aplicou um volume de água de $50 \mathrm{~L}$; após a drenagem do excesso de água, colocaram-se os $20 \%$ restantes e, após 30 min, fez-se a compactação da camada de solo.

O solo foi coletado do horizonte A de um Latossolo Vermelho-Amarelo das imediações da localidade denominada Tiro-de-Guerra, do município de Viçosa, MG, de onde foram retiradas amostras para análise de algumas de suas características físicas, sendo os resultados apresentados na Tabela 1.

Tabela 1. Características físicas do solo utilizado

\begin{tabular}{|c|c|c|c|c|c|c|}
\hline \multirow{3}{*}{$\begin{array}{l}\text { Profundidade } \\
\mathrm{cm}\end{array}$} & \multicolumn{6}{|c|}{ Granulometria } \\
\hline & Argila & Areia Fina & Areia Grossa & Silte & Densidade Aparente $(\rho)$ & Textura \\
\hline & \multicolumn{4}{|c|}{$\mathrm{dag} \mathrm{kg}^{-1}$} & \multicolumn{2}{|l|}{$\mathrm{kg} \mathrm{dm}^{-3}$} \\
\hline $0-20$ & 68 & 10 & 15 & 7 & 1,06 & Muito Argilosa \\
\hline
\end{tabular}


O canal de solo utilizado nos ensaios apresenta dimensões de $1 \mathrm{~m}$ de comprimento, $0,7 \mathrm{~m}$ de largura e $0,25 \mathrm{~m}$ de altura, sendo o mesmo apoiado em cavaletes dotados de sistema telescópio, para possibilitar a variação da declividade, e uma calha para condução do escoamento superficial, conforme descrito por Amorim (1999).

As aplicações da precipitação foram realizadas utilizando-se o simulador de chuvas desenvolvido por Alves Sobrinho (1997) equipado com bocais tipo Veejet 80.100 , com pressão de serviço fixada em $32,75 \mathrm{kPa}$, sob o qual o canal de solo foi locado a uma altura de $2,5 \mathrm{~m}$ do bico do simulador. Realizaram-se testes preliminares para obtenção das precipitações desejadas, com o auxílio de uma calha de área igual à do canal $\left(0,7 \mathrm{~m}^{2}\right)$ e locada na mesma posição do canal de solo. A intensidade de precipitação média foi determinada pela relação entre o volume de água coletado na calha durante o intervalo de tempo estabelecido e a área da calha de coleta.

Para cada intensidade de precipitação utilizada no estudo de perda de solo, determinou-se a uniformidade de distribuição de água pelo simulador de chuvas, empregando-se o coeficiente de uniformidade de Christiansen (Christiansen, 1942).

Antes da realização de cada teste procedeu-se à aplicação de uma lâmina d'água de $100 \mathrm{~mm}$, para saturação do solo, tendo em vista que esta condição é considerada crítica para a ocorrência de escoamento superficial e perdas de solo. Para evitar que durante a saturação do solo ocorressem alterações drásticas da sua superfície, a mesma foi protegida com uma manta sintética de alta permeabilidade (Bidim).

$\mathrm{O}$ experimento consistiu de um esquema fatorial, no qual o material de solo foi submetido a cinco distintos valores de energia cinética, correspondentes às intensidades de precipitação de $30,46,69,88$ e $107 \mathrm{~mm} \mathrm{~h}^{-1}$, respectivamente, com duração de 58 min, e cinco declividades da superfície do solo $(2,6,10,14$ e 18\%).

\section{Determinação da energia cinética das precipitações}

A energia de impacto da chuva simulada sobre o solo, por unidade de área, foi estimada por meio da Eq. 1, proposta por Stillmunkes \& James (1982).

$$
\mathrm{E}_{\mathrm{c} / \mathrm{a}}=\frac{1}{2} \rho_{\mathrm{w}} \mathrm{Lv}^{2}
$$

em que:

$$
\begin{array}{ll}
\mathrm{E}_{\mathrm{c} / a} & \text { - energia cinética por unidade de área, } \mathrm{M} \mathrm{T}^{-2} \\
\rho_{\mathrm{w}} & \text { - massa específica da água, } \mathrm{M} \mathrm{L}^{-3} \\
\mathrm{~L} & \text { - lâmina média de água aplicada pelos bocais, } \mathrm{L} \\
\mathrm{v} & \text { - velocidade média de impacto das gotas de chuva, } \mathrm{LT}^{-1}
\end{array}
$$

Determinou-se, também, a energia cinética da chuva natural pela Eq. 2, proposta por Wischmeier \& Smith (1958) para fins de comparação com a energia cinética da chuva simulada.

$$
\begin{array}{ll}
\mathrm{EcN}=(17,124+5,229 \log \mathrm{I}) \text { It } & \text { para } \mathrm{I}<76 \\
\mathrm{EcN}=(17,124+5,229 \log 76) \text { It } & \text { para } \mathrm{I} \geq 76
\end{array}
$$

em que:

$\mathrm{EcN}$ - é a energia cinética da chuva natural por unidade de área, $\mathrm{J} \mathrm{m}^{-2}$
I $\quad$ - intensidade de precipitação, $\mathrm{mm} \mathrm{h}^{-1}$

t - tempo de precipitação h.

\section{Velocidade de impacto das gotas na superfície do solo}

Partindo-se do pressuposto de que o jato d'água se fraciona em gotas de diâmetros diferentes ao sair de um bocal estimou-se, com base nos fundamentos da hidrodinâmica, a velocidade de impacto da gota com a superfície do solo. A equação diferencial que caracteriza a trajetória de uma gota que deixa um bocal posicionado verticalmente para baixo, pode ser representada, segundo o Princípio Fundamental da Dinâmica, da seguinte forma:

$$
m \frac{d^{2} y}{{d t^{2}}^{2}}=m g-m f
$$

em que:

$$
\begin{array}{ll}
\mathrm{m} & \text { - massa da gota, } \mathrm{M} \\
\mathrm{y} & \text { - altura de queda da gota, } \mathrm{L} \\
\mathrm{g} & \text { - aceleração da gravidade, } \mathrm{L} \mathrm{T}^{-2} \\
\mathrm{f} & \text { - resistência de arrastamento, } \mathrm{L} \mathrm{T}^{-2} \\
\mathrm{t} & \text { - tempo, } \mathrm{T}
\end{array}
$$

A resistência do ar ao deslocamento da gota foi calculada a partir da relação entre a velocidade da gota e o coeficiente de arraste, proposta por Seginer (1965)

$$
\mathrm{f}=\mathrm{C}_{\mathrm{n}} \mathrm{v}^{\mathrm{n}}
$$

em que:

$$
\begin{gathered}
\mathrm{C}_{\mathrm{n}} \text { - coeficiente de arraste, cuja dimensão depende do } \\
\text { valor de } n .
\end{gathered}
$$

Substituindo-se a Eq. 5 na Eq. 4 e se procedendo às devidas simplificações, tem-se

$$
\frac{d^{2} y}{d t^{2}}=g-C_{n} v^{n}
$$

A variação da velocidade das gotas no tempo foi descrita pela equação diferencial

$$
\frac{d^{2} y}{d t^{2}}=\frac{d v}{d t}
$$

A velocidade de uma gota proveniente de um bico que, posicionado a uma altura y em relação ao solo, pulveriza a água verticalmente para baixo, foi estimada fazendo-se $n=2$ e igualando as Eqs. 6 e 7

$$
\frac{\mathrm{d} v}{\mathrm{dt}}=\mathrm{g}-\mathrm{C}_{2} \mathrm{v}^{2}
$$

A velocidade foi estimada com a solução da Eq. 8, utilizando-se a técnica númerica de Runge-Kutta de quarta 
ordem. Para tal, utilizou-se uma sub-rotina do programa ENERCHUVA, desenvolvido por Alves Sobrinho (1997).

Para a estimativa do coeficiente de arraste modificado em função do diâmetro da gota, empregou-se a relação entre $\mathrm{C}_{2}$ e o diâmetro da gota, proposta por Hills \& Gu (1989):

$$
\mathrm{C}_{2}=0,4671 \mathrm{~d}^{-0,9859}
$$

em que dé o diâmetro médio da gota, mm.

A velocidade inicial da gota foi calculada pela equação:

$$
\mathrm{V}_{0}=\mathrm{C}_{\mathrm{d}}\left(\frac{2 \mathrm{gP}}{\gamma}\right)^{0,5}
$$

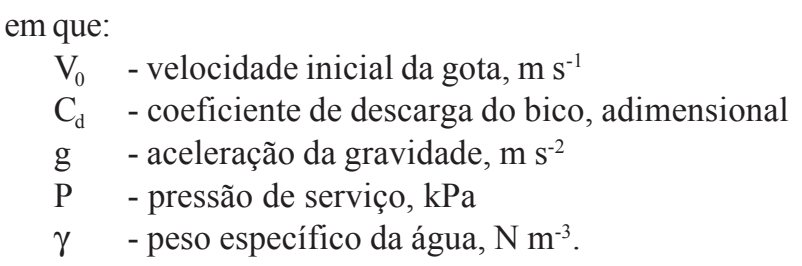

\section{Distribuição do diâmetro de gotas da precipitação}

A distribuição do diâmetro médio das gotas da precipitação foi determinada para as intensidades de precipitação aplicadas com o simulador de chuvas operando com pressão de 32,75 $\mathrm{kPa}$, numa altura 2,5 m em relação à superfície do solo no canal. O método utilizado na estimativa da distribuição de tamanho de gotas foi o da farinha, conforme descrito por Oliveira (1991).

\section{Determinação das perdas de solo}

As perdas de solo foram determinadas pelo método direto, por meio da quantificação do solo arrastado pelo escoamento superficial. O solo foi coletado a cada intervalo de $2 \mathrm{~min}$, por um período de $30 \mathrm{~s}$, sendo feitas coletas por um período total de 58 min de precipitação.

Para a coleta do solo utilizou-se o filtro de café Mellita, previamente pesado, colocado em uma armação de tela e apoiado em um copo de plástico descartável. Após a coleta, esperou-se completar a filtragem de todo o líquido coletado para, então, colocar o filtro com solo em estufa a $105^{\circ} \mathrm{C}$, por aproximadamente $36 \mathrm{~h}$, para posterior determinação da massa seca.

Para quantificação do solo em suspensão que passou pelo material filtrante, utilizou-se o método da pipeta, em que todo o volume de escoamento superficial que passou pelo filtro foi agitado e, com o auxílio de uma pipeta volumétrica, retirou-se uma alíquota de $50 \mathrm{~mL}$. A alíquota coletada foi posta em uma lata, previamente pesada, e levada a estufa a $105^{\circ} \mathrm{C}$, por aproximadamente $36 \mathrm{~h}$, para posterior determinação da concentração de solo em suspensão. Com base no volume total escoado durante o tempo de coleta, obteve-se a massa de solo seco que passou pelo material filtrante. A massa total de solo seco foi obtida por meio do somatório do solo retido no material filtrante e do solo em suspensão na solução que passou pelo filtro.

\section{Estabelecimento dos modelos de regressão}

Realizaram-se análises de regressão utilizando-se o programa estatístico "SAEG", desenvolvido pela Universidade Federal de Viçosa, com o objetivo de se conseguir equações matemáticas ajustadas aos dados obtidos, tendo-se como variável dependente a perda de solo e, independentes, a declividade e a energia cinética decorrentes das precipitações aplicadas ao solo.

\section{RESULTADOS E DISCUSSÃO}

\section{Energia cinética das precipitações}

$\mathrm{Na}$ Figura 1 estão apresentadas as curvas e equações de caracterização da energia cinética aplicada pelo simulador de chuvas e calculada para a chuva natural, para as condições de intensidade de precipitação utilizadas nos testes. Analisando-se esta figura, pode-se observar que a energia cinética da chuva simulada foi menor que a da chuva natural atingindo, em média, $68 \%$ da energia cinética da chuva natural apresentando, para a faixa de intensidade de precipitação de 30 a $107 \mathrm{~mm} \mathrm{~h}^{-1}$, uma pequena variação em torno da média da diferença relativa entre chuva simulada e natural. Uma vez que no processo de erosão entre sulcos o desprendimento das partículas do solo se dá principalmente pela ação erosiva do impacto das gotas da chuva na superfície do solo, é importante conhecer o valor de energia cinética da chuva simulada nos estudos do processo erosivo em condições de laboratório, pois uma chuva com determinado valor de energia cinética proporciona certo valor de desprendimento de partículas de solo, independentemente se a chuva é simulada ou natural; no entanto, quando se trabalha apenas com intensidade de precipitação, tal afirmativa não poderia ser feita, uma vez que se teria energias de impacto bastante diferenciadas entre as chuvas simulada e natural para uma mesma intensidade.

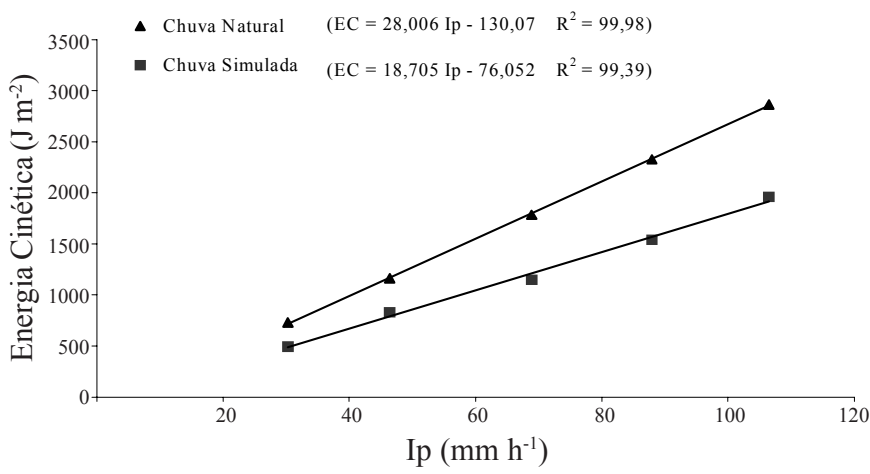

Figura 1. Energia cinética das chuvas produzidas com uso do simulador e calculada para a chuva natural, em função das intensidades de precipitação (Ip) utilizadas no experimento

Este tipo de observação também foi feita por Meyer \& Harmom (1992) os quais evidenciaram a importância da energia cinética da chuva simulada para avaliar o processo de erosão entre sulcos, visto que dificilmente se consegue reproduzir as características da chuva natural, principalmente para intensidades elevadas.

\section{Perdas de solo}

Tem-se, nas Figuras 2A a 2E, as curvas e equações ajustadas referentes aos valores de perda acumulada de solo, em função do tempo de precipitação e da energia cinética decorrente das 
precipitações, para as declividades da superfície do solo de 2 , $6,10,14$ e $18 \%$, respectivamente.

\section{(A)}
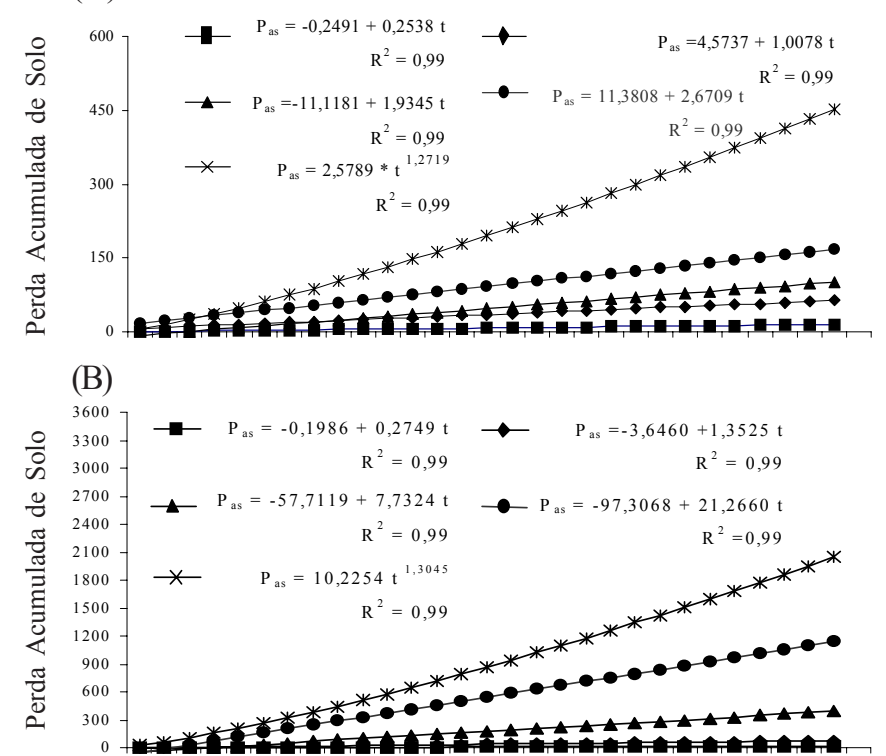

(C)

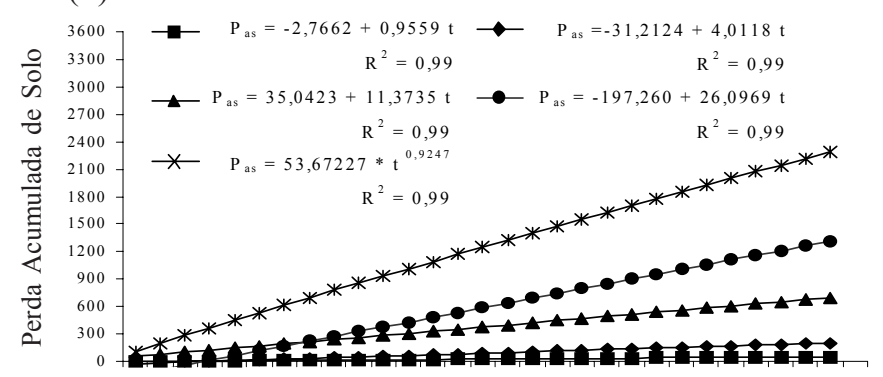

(D)

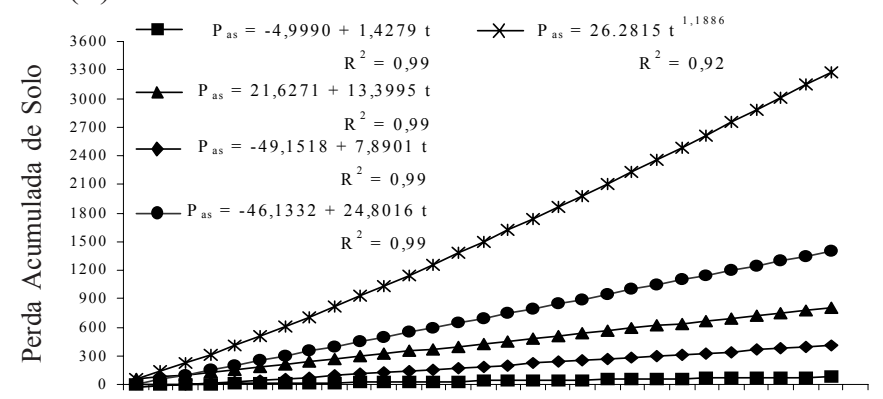

(E)

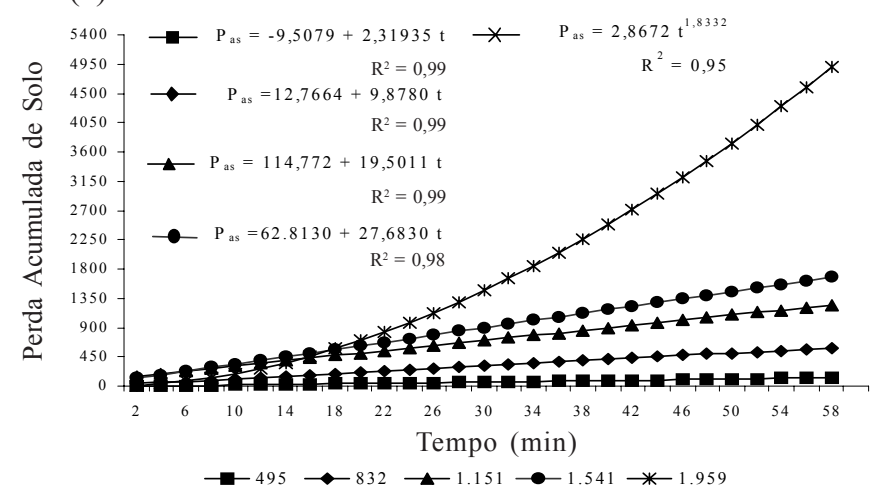

Figura 2. Perda acumulada de solo $\left(\mathrm{P}_{\mathrm{as}}\right), \mathrm{g} \mathrm{m}^{-2}$, em função do tempo de precipitação $(\mathrm{t})$, min, e da energia cinética, $\mathrm{J} \mathrm{m}^{-2}$, para superfícies do solo com diferentes declividades (A) $2 \%$, (B) $6 \%$, (C) $10 \%$, (D) $14 \%$ e (E) $18 \%$
Analisando-se as Figuras 2A a 2E observa-se, de modo geral, uma tendência de aumento linear da perda acumulada de solo com o tempo de precipitação. Mermut et al. (1997) também observaram esse mesmo tipo de tendência para intensidades de precipitação de 40 e $100 \mathrm{~mm} \mathrm{~h}^{-1}$. Esta linearidade da perda acumulada de solo em função do tempo indica que, na modelagem do processo erosivo, pode-se considerar uma taxa de perda de solo em áreas entre sulcos constante ao longo do tempo, embora para o valor de energia cinética de $1.959 \mathrm{~J} \mathrm{~m}^{-2}$ esta tendência tenha sido potencial, porém com expoente próximo da unidade.

Para a declividade da superfície do solo de 2\% (Figura 2A) observa-se aumento linear da perda acumulada de solo ao longo do tempo de precipitação para os eventos com valores de energia cinética aplicada de 495 a $1.540 \mathrm{~J} \mathrm{~m}^{-2}$, correspondendo às intensidades de precipitação de $30 \mathrm{a} 88 \mathrm{~mm} \mathrm{~h}^{-1}$, respectivamente mostrando, com isto, que, para esta faixa de variação da energia cinética, a taxa de perda de solo é constante ao longo do tempo; no entanto, para o valor de energia cinética aplicada de $1.959 \mathrm{~J} \mathrm{~m}^{-2}$, o qual está associado à maior intensidade de precipitação $\left(107 \mathrm{~mm} \mathrm{~h}^{-1}\right)$, verificou-se tendência potencial, apresentando taxa de perda de solo crescente ao longo do tempo. Este mesmo comportamento foi verificado para as demais declividades (Figuras 2B, 2C, 2D e 2E). Tal mudança de comportamento observada no maior valor de energia cinética $\left(1.959 \mathrm{~J} \mathrm{~m}^{-2}\right)$ deve-se, provavelmente, ao aumento da vazão de escoamento superficial produzida por esta intensidade de precipitação, o que pode estar ocasionando a concentração do escoamento e, conseqüentemente, a formação de caminhos preferenciais de escoamento da água aumentando, com isto, a sua capacidade de transporte.

Verifica-se, para a declividade da superfície do solo de $2 \%$ (Figura 2A) que a taxa de perda de solo para a energia cinética de $1.540 \mathrm{~J} \mathrm{~m}^{-2}$ foi 11,5 vezes maior que a correspondente à energia cinética de $495 \mathrm{~J} \mathrm{~m}^{-2}$. Considerando-se a taxa média de perda de solo, correspondente à energia cinética de $1.959 \mathrm{~J} \mathrm{~m}^{-2}$, observa-se aumento de cerca de 31 vezes na perda, quando comparada ao valor de $495 \mathrm{~J} \mathrm{~m}^{-2}$.

$\mathrm{Na}$ Figura 2B, referente à declividade da superfície do solo de $6 \%$, verifica-se que a taxa de perda de solo para a energia cinética aplicada de $1.959 \mathrm{~J} \mathrm{~m}^{-2}$ foi 129 vezes maior que para a energia cinética de $495 \mathrm{~J} \mathrm{~m}^{-2}$. Para a declividade da superfície do solo de $10 \%$ (Figura 2C) a taxa de perda de solo para a energia cinética de $1.959 \mathrm{~J} \mathrm{~m}^{-2}$ foi 43 vezes maior que a correspondente à energia cinética de $495 \mathrm{~J} \mathrm{~m}^{-2}$. Para a declividade de $14 \%$ (Figura 2D) a superioridade relativa da taxa de perda de solo correspondente à energia cinética de $1.959 \mathrm{~J} \mathrm{~m}^{-2}$, quando comparada com a energia cinética de $495 \mathrm{~J} \mathrm{~m}^{-2}$, foi de 42 vezes, enquanto para declividade de $18 \%$ (Figura 2E), esta superioridade relativa foi menor, sendo de aproximadamente 39 vezes caracterizando, desta forma, redução na diferença relativa observada entre as taxas de perda de solo obtidas entre os maiores e menores valores de energia cinética, a medida em que a declividade aumentou. Esta redução pode ser explicada, provavelmente, pela capacidade de transporte de partículas de solo pelo escoamento superficial, ou seja, quando se tem baixa declividade da superfície do solo tem-se, também, escoamento com baixa velocidade e, conseqüentemente, a capacidade de transporte fica limitada à vazão de escoamento. Com isto, quando 
se comparam baixos valores de energia cinética (para as condições estudadas, correspondentes a baixas intensidades de precipitação) com valores mais elevados, tem-se maior diferença na taxa de perda de solo, em função do aumento na vazão de escoamento; no entanto, quando se aumentou a declividade da superfície do solo, outro componente passou a incrementar a capacidade de transporte de sedimentos, pelo aumento na velocidade do escoamento superficial. Este incremento foi igual para todos os valores de energia cinética aplicados, tendendo a diminuir, com isto, a diferença entre as taxas de perda de solo entre os valores extremos de energia cinética para as maiores declividades.

$\mathrm{Na}$ Tabela 2 estão apresentados os valores de perda total de solo obtidos experimentalmente, em função da energia cinética decorrente das precipitações e da declividade da superfície do solo, para precipitações com 58 min de duração.

Tabela 2. Perdas de solo, $\mathrm{g} \mathrm{m}^{-2}$, em função da energia cinética decorrente das precipitações e da declividade da superfície do solo (DEC) para precipitações com duração de $58 \mathrm{~min}$

\begin{tabular}{crrrrr} 
DEC & \multicolumn{5}{c}{ Energia Cinética $\left(\mathrm{J} \mathrm{m}^{-2}\right)$} \\
\cline { 2 - 6 }$(\%)$ & \multicolumn{1}{c}{495} & 832 & 1.150 & 1.540 & 1.959 \\
\hline 2 & 14,3 & 61,6 & 112,6 & 168,3 & 524,8 \\
6 & 15,8 & 71,5 & 416,8 & $1.123,5$ & $1.900,6$ \\
10 & 53,3 & 206,5 & 660,2 & $1.348,3$ & $2.385,9$ \\
14 & 79,8 & 440,6 & 770,3 & $1.389,4$ & $2.634,4$ \\
18 & 124,5 & 563,2 & $1.207,0$ & $1.568,7$ & $3.460,1$ \\
\hline
\end{tabular}

Analisando-se o efeito isolado da energia cinética na perda total de solo, observa-se aumento de 36,$7 ; 120,2 ; 44,7 ; 33$ e 27,8 vezes na perda de solo, quando o valor de energia cinética foi aumentado de 495 para $1.959 \mathrm{~J} \mathrm{~m}^{-2}$, para as declividades da superfície do solo de 2, 6, 10, 14 e 18\%, respectivamente.

Pode-se observar, ainda, que a declividade da superfície do solo apresentou, isoladamente, efeito menos expressivo na perda total de solo, quando comparado ao da energia cinética, resultando num aumento de perda de solo de 8,$7 ; 9,1 ; 10,7 ; 9,3$ e 6,6 vezes, para os valores de energia cinética de 495, 832, $1.150,1.540$ e $1.959 \mathrm{~J} \mathrm{~m}^{-2}$, respectivamente, quando a declividade foi aumentada de 2 para $18 \%$. Esta menor importância relativa da declividade da superfície na perda de solo, em áreas entre sulcos, foi também observada por Lattanzi et al. (1974) devendo-se ao fato de que, na erosão entre sulcos, o processo de desprendimento de partículas de solo ocorre devido à energia de impacto das gotas da chuva, sendo o escoamento responsável apenas pelo transporte das partículas desprendidas; entretanto, ao se analisar o efeito conjunto desses dois fatores, verifica-se aumento expressivo da perda de solo, da ordem de 289 vezes, quando se compara o teste com $2 \%$ de declividade da superfície do solo e energia cinética de $495 \mathrm{~J} \mathrm{~m}^{-2}$ com o teste de $18 \%$ e $1.959 \mathrm{~J} \mathrm{~m}^{-2}$.

$\mathrm{O}$ aumento observado na perda de solo, quando a declividade da superfície do solo foi aumentada, tendo a taxa de escoamento permanecido constante ao longo de todo o teste, pode ser devido a três fatores: ao aumento no desprendimento de partículas de solo provocado pelo maior ângulo de impacto das gotas da chuva sobre a superfície do solo; à maior facilidade com que as partículas se movimentam no sentido da declividade pelo efeito da gravidade, para maiores declividades da superfície do solo; e ao aumento da velocidade de escoamento superficial, o qual aumenta a capacidade de transporte do escoamento (Lattanzi et. al., 1974; Grosh \& Jarret, 1994).

$\mathrm{Na}$ Figura 3A estão apresentadas as curvas de perda de solo em função da energia cinética decorrente das precipitações e das declividades estudadas, para precipitações com $58 \mathrm{~min}$ de duração. Observa-se, nesta figura, que a perda de solo aumenta com o aumento da energia cinética aplicada, sendo este aumento uma função potencial do valor da energia cinética, com expoentes maiores que dois $(2,31$ - 3,67). Verifica-se, também, que, a medida em que a declividade cresce, o incremento da perda de solo, em termo absoluto, em função do aumento da energia cinética, é mais acentuado.

$\mathrm{Na}$ Figura 3B tem-se as curvas de perda de solo em função da declividade, para cada valor de energia cinética avaliada. Observase que a perda de solo aumentou com o acréscimo da declividade, sendo este aumento função exponencial do valor da declividade para valores de energia cinética de 495 e $832 \mathrm{~J} \mathrm{~m}^{-2}$ e potencial, com expoentes próximo de um $(0,83-1,04)$ para valores de energia cinética de $1.151,1.541$ e $1.959 \mathrm{~J} \mathrm{~m}^{-2}$, mostrando tendência à linearidade. Observa-se, nesta figura, efeito menos expressivo da declividade nas perdas de solo; entretanto, quando se faz uma análise do efeito conjunto das duas variáveis sobre a perda de solo, nota-se aumento acentuado, evidenciando a importância do efeito desses dois fatores sobre a perda de solo,
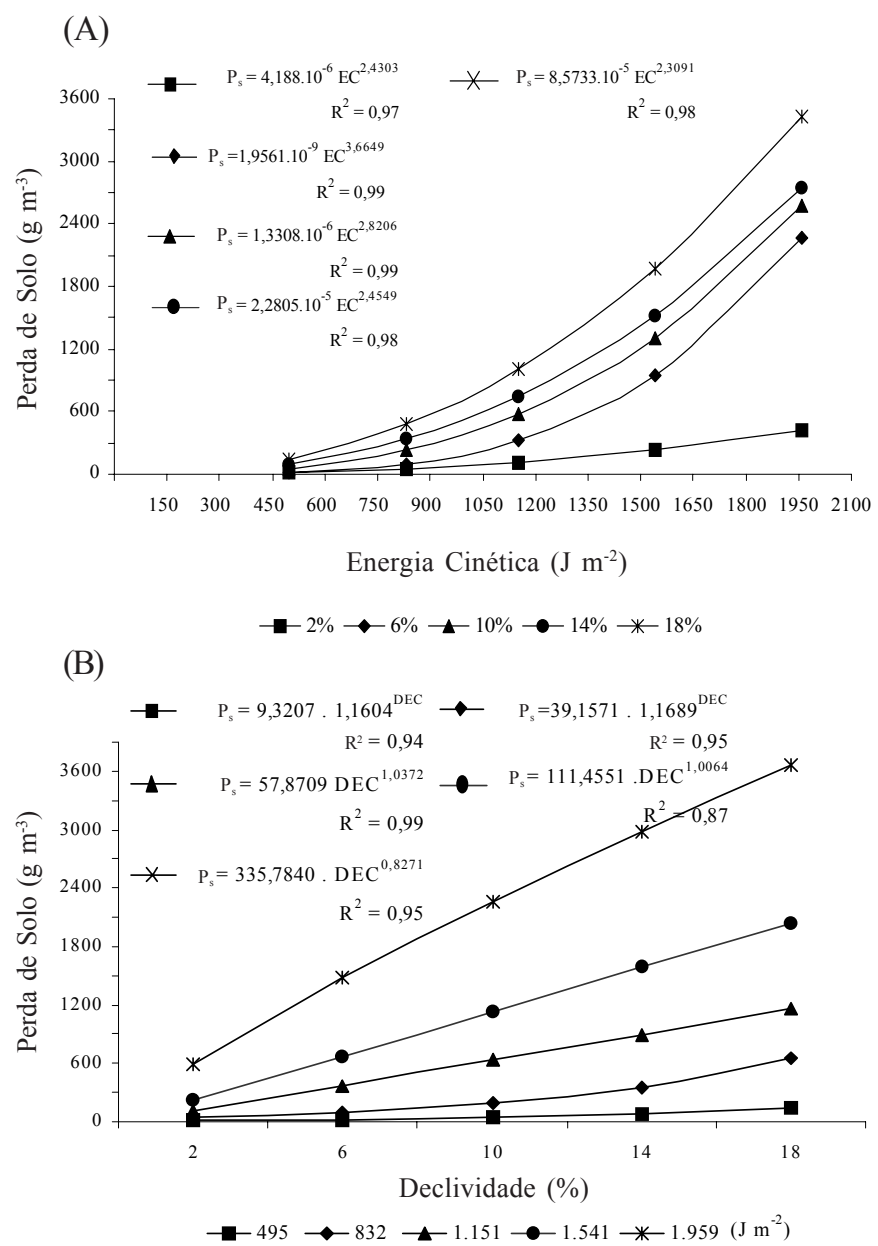

Figura 3. Perda de solo (Ps), g m², em função da (A) energia cinética (EC) decorrente das precipitações, e da declividade da superfície do solo e (B) declividade da superfície do solo (DEC) e da energia cinética decorrente da precipitação, para precipitação com duração de 58 min 
cuja interação é decorrente da influência direta e indireta dos dois fatores na capacidade de transporte do escoamento superficial. A energia cinética influencia no desprendimento de partículas de solo e na vazão de escoamento, visto que, para as condições estudadas, a mesma está associada a maiores lâminas aplicadas, enquanto a declividade da superfície do solo influencia na velocidade do escoamento superficial.

Na tentativa de se expressar o efeito desta interação, fez-se o ajuste de equações de perda de solo em função da energia cinética da chuva e da declividade da superfície do solo. Dentre as diversas equações avaliadas, a que apresentou melhor coeficiente de ajuste e, quando aplicada para as condições estudadas, apresentou menor desvio em relação aos dados observados experimentalmente, foi

$$
\text { Ps }=0,00028 \mathrm{DEC}^{0,64105} \mathrm{E}_{\mathrm{c} / \mathrm{a}}^{1,89622}
$$

em que:

Ps - massa de partículas de solo desprendidas e transportadas, $\mathrm{g} \mathrm{m}^{-2}$

DEC - declividade da superfície do solo, $\%$

$\mathrm{E}_{\mathrm{c} / \mathrm{a}}$ - energia cinética por unidade de área, $\mathrm{J} \mathrm{m}^{-2}$.

Esta equação vem confirmar as observações anteriores de que a perda de solo aumenta com o incremento da intensidade de precipitação e da declividade da superfície do solo e, também, o efeito menos expressivo da declividade na perda de solo quando comparado com o da energia cinética, tendo em vista que a declividade apresenta valor de expoente inferior ao da energia cinética.

\section{CONCLUSÕES}

Os resultados obtidos permitiram concluir-se que:

1. As chuvas simuladas utilizadas neste trabalho apresentaram energia cinética, em média, $32 \%$ menor que a da chuva natural, para a faixa de intensidade de precipitação de 30 a $107 \mathrm{~mm} \mathrm{~h}^{-1}$.

2. Com exceção do maior valor de energia cinética $\left(1.959 \mathrm{~J} \mathrm{~m}^{-2}\right)$ a perda acumulada de solo, ao longo do tempo apresentou, de modo geral, comportamento linear proporcionando, desta forma, taxas de perda de solo constantes ao longo dos testes.

3. A perda total de solo aumenta com o incremento da energia cinética da precipitação e da declividade da superfície do solo, sendo que a declividade apresentou efeito menos expressivo na perda total de solo comparado ao da energia cinética, resultando num aumento médio de perda de solo de, aproximadamente, nove vezes, quando a declividade da superfície do solo aumentou de 2 para $18 \%$.

4. A perda total de solo correspondente à energia cinética de $1.959 \mathrm{~J} \mathrm{~m}^{-2}$ foi, em média, 37 vezes maior que a correspondente à energia cinética de $495 \mathrm{~J} \mathrm{~m}^{-2}$.

5. O efeito da interação entre a declividade da superfície do solo e energia cinética é bastante expressivo, proporcionando um aumento de 242 vezes na perda de solo, para as condições extremas utilizadas neste trabalho.

6. Para as condições estudadas neste trabalho, a perda de solo entre sulcos $\left(\mathrm{P}_{\text {as }}, \mathrm{g} \mathrm{m}^{-2}\right)$ para as diferentes condições de declividade (DEC, \%) e energia cinética da precipitação $\left(\mathrm{E}_{\mathrm{c} / \mathrm{a}}, \mathrm{J} \mathrm{m}^{-2}\right)$ pode ser estimada pela equação.

$$
\text { Ps }=0,00028 \operatorname{Dec}^{0,64105} E_{\mathrm{c} / \mathrm{a}}^{1,89622} \quad \mathrm{R}^{2}=0,97
$$

\section{LITERATURA CITADA}

Alves Sobrinho, T. Desenvolvimento de um infiltrômetro de aspersão portátil. Viçosa, MG: UFV, 1997. 85p. Tese Doutorado

Amorim, R.S.S. Desprendimento e arraste de partículas de solo decorrentes de chuvas simuladas. Viçosa, MG: UFV, 1999. 75 p. Dissertação Mestrado

Bertoni, J.; Lombardi Neto, R. Conservação do solo. São Paulo: Ícone, 1990.355p.

Bryan, R.B. The influence of slope angle on soil entrainment by sheetwash and rainsplash. Earth Surface Process, Philadelphia, v.4, n.1, p.43-58, 1979.

Christiansen, J.P. Irrigation by sprinkling. Berkeley: University of California Agricultual Experiment Station, 1942. 124p. Bulletin, 670.

Foster, G.R. Modelling the erosion process. In: Haan, C.T; Johnson. H.P.; Brakensienk, D.L. (ed). Hydrologic modelling of small watersheds, St. Joseph, Mich.: ASAE, 1982. p. 296380. ASAE Monograph, 5

Grosh, J.L.; Jarrett, A.R. Interril erosion and runoff on very steep slopes. Transactions of the ASAE, St Joseph, v.37, n.4, p.1127-1133, 1994.

Hills, D.J.; Gu, Y. Sprinkler volume mean droplet diameter as a function of pressure. Transactions of the ASAE, St Joseph, v.32, n.2, p.471-476, 1989.

Kinnell, P.I.A.; Cummings, D. Soil slope gradient interactions in erosion by rain-impacted flow. Transactions of the ASAE, St Joseph, v.36, n.2, p.381-387, 1993.

Lang, K.J.; Prunty, L; Schroeder, S.A.; Disrud, L.A. Interrill erosion as an index of mined land erodibility. Transactions of the ASAE, St Joseph, v.27, n.1, p.99-101, 1984.

Lattanzi, A.R.; Meyer, L.D.; Baumgardner, M.F. Influences of mulch rate and slope steepness on interrill erosion. Soil Science Society of America. Journal, Madison, v. 38, n. 6, p. 946-950, 1974.

Mermut, A.R.; Luk, S.H.; Romkens, M.J.M.; Poesen, J.W.A. Soil loss by splash and wash during rainfall from two loess soils. Geoderma, Amsterdam, v.75, n.3, p.203-214, 1997.

Meyer, L.D.; Harmon, W.C. Interrill runoff and erosion: Effects of row-sideslope shape, rain energy, and rain intensity. Transactions of the ASAE, St Joseph, v.35, n.4, p.1199-1203, 1992.

Meyer, L.D.; Wischmeier, W.H. Mathematical simulation of the process of soil erosion by water. Transactions of the ASAE, St Joseph, v.12, n.6, p. 754-758, 1969.

Oliveira, R.A. Distribuição de gotas por tamanho e perfil de precipitação de um aspersor fixo. Viçosa, MG: UFV, 1991. 103p. Dissertação Mestrado.

Parker, D.B.; Michel, T.G.; Smith, J.L. Compaction and water velocity effects on soil in shallow flow. Journal of Irrigation and Drainage Engineering, New York, v.121, n.2, p.170-178, 1995.

Seginer, I. Tangencial velocity of sprinkler drops. Transactions of the ASAE, St Joseph, v.8, n.1, p.90-93, 1965.

Stillmunkes, R.T.; James, L.G. Impact energy of water droplets from irrigation sprinklers. Transactions of the ASAE, St Joseph, v.25, n. 1, p. 130-133, 1982.

Watson, D.A.; Laflen, J.M. Soil strength, slope, and rainfall intensity effects on interrill erosion, Transactions of the ASAE, St Joseph, v.29, n.1, p.98-102, 1986.

Wischmeier, W.H.; Smith, D.D. Rainfall energy and its relationship to soil loss. Transactions, American Geophysical Union, Portland, v. 39, n. 2, p. 285-280, 1958. 